\title{
O QUE É CRÍTICO NA SOCIOLOGIA CRÍTICA?*
}

\author{
Josué Pereira da Silva \\ Universidade Estadual de Campinas (Unicamp), Campinas - SP, Brasil. E-mail: josueps@unicamp.br
}

DOI: http//dx.doi.org/10.17666/329301/2017

O que entendo aqui por sociologia crítica situa-se em pelo menos dois sentidos: no limite entre sociologia e teoria social; no limite de um mundo marcado por um conjunto de crises, que vai da ecológica à civilizacional, passando pelas dimensóes econômi-

* Uma versão preliminar deste texto foi apresentada no 38o Encontro Anual da Anpocs, no GT 40: Teoria social no limite: novas frentes/fronteiras na teoria social contemporânea, coordenado por Carlos Eduardo Sell e Emill A. Sobottka, em Caxambu (MG), em outubro de 2014; também o apresentei como conferência de abertura no 2o Fórum do Programa de Pós-Graduação em Sociologia do Instituto de Filosofia e Ciências Humanas da Universidade Estadual de Campinas (IFCH-Unicamp) em 26/5/2015. Gostaria de agradecer aos participantes dos dois eventos, pelos comentários críticos e pelas questôes que contribuíram para eu aprofundar minhas reflexôes sobre o tema. Agradeço também aos pareceristas anônimos, cujas críticas me levaram a elaborar alguns acréscimos e precisóes ao texto originalmente apresentado para publicação.

Artigo recebido em 28/09/2015

Aprovado em 25/08/2016 ca, cultural, política e social. ${ }^{1} \mathrm{O}$ primeiro sentido, que pode ser definido como teórico-epistemológico, refere-se à própria natureza interdisciplinar da maioria dos modelos ou das abordagens que se autodenominam teorias críticas; o segundo sentido pode ser definido como político-normativo, na medida em que aponta, ou deve apontar, para algum horizonte além da sociedade existente. Com base nisso, creio que a classificação dos autores objetos do presente texto como filósofos e/ou sociólogos não é para mim de grande relevância, já que todos eles são teóricos sociais, cujas abordagens não se limitam à fronteira de uma única disciplina. ${ }^{2}$

Dito isso, parto para uma apresentação mais direta das reflexóes que pretendo desenvolver e cujo ponto de partida é a intuição, ou hipótese, de que presenciamos nas últimas décadas uma intensificação da produção de textos e de abordagens teóricas, marcados ou caracterizados por uma forte ênfase na dimensão normativa (Genard, 2015; Silva, 2012). ${ }^{3}$ 
Não quero assim, evidentemente, dar a entender que não tenha havido antes uma grande variedade de textos e de abordagens com perfil normativo, mas que na teoria social e na sociologia contemporâneas a balança parece pender cada vez mais para preocupaçóes de natureza normativa. Isso - que muito provavelmente se deve ao próprio contexto histórico que vivemos desde a emergência dos chamados novos movimentos sociais, a ascensão do neoliberalismo e a queda do Muro de Berlim - parece evidenciado, sobretudo, pela crescente visibilidade tanto de temas como democracia, cidadania, reconhecimento, justiça, igualdade, identidade e diferença como pela emergência de proposiçóes teóricas, mais ou menos ambiciosas, mais ou menos abrangentes, que se autodenominam críticas e que, de alguma maneira, recorrem às ideias de emancipação, autonomia, autodeterminação e justiça. Embora essa hipótese seja um tanto intuitiva, creio que o crescente interesse em temas com teor normativo ocorre também internamente às obras de alguns autores; para isso basta observar, por exemplo, a evolução das publicaçóes de Jeffrey Alexander e, entre nós, de José Maurício Domingues.

Baseio-me, aqui, sobretudo nas teorias de Axel Honneth, Nancy Fraser, Alain Caillé e Boaventura de Sousa Santos, embora não deixe de fazer, ao longo deste texto, referência a outras teorias e abordagens contemporâneas. ${ }^{4}$ Entretanto, deixo claro desde já que minha intenção não é fazer um balanço dessas abordagens, mas, a partir de um eixo norteador, discutir alguns aspectos dessas teorias com base em três ideias, ou hipóteses, que me permitem avaliá-las como contribuiçóes para uma sociologia crítica capaz de responder satisfatoriamente às demandas do presente.

Para tanto, apresento a seguir as três ideias básicas em torno das quais procuro um núcleo comum a essas abordagens autodenominadas críticas, assim como o eixo que guiará minha análise. A primeira ideia que me parece comum a essas teorias pode ser, grosso modo, expressa como a busca de um paradigma intersubjetivo ou interacionista que tenta se diferenciar das abordagens holista e/ou individualista, reivindicando, no âmbito teórico, o estatuto de um terceiro paradigma, alternativo aos dois últimos (I). Ao afirmar que as quatro abordagens aqui dis- cutidas são intersubjetivas, não quero dizer que elas partilham a mesma concepção de intersubjetividade ou que sejam intersubjetivas em grau e maneira semelhantes. Mas em todas elas é inegável a busca de distanciamento tanto em relação às abordagens puramente individualistas quanto em relação àquelas mais estritamente holistas. Em minha leitura, a estratégia de realçar a intersubjetividade como um substrato comum não significa, portanto, eliminar as diferenças entre elas, tampouco dizer que partilham uma mesma concepção de intersubjetividade. Se a identificação de uma "intersubjetividade forte" pode ser facilmente encontrada na obra de Honneth, ${ }^{5}$ cuja teoria do reconhecimento está ancorada em autores como Hegel e Mead, isso não significa, por outro lado, que as outras teorias aqui abordadas não sejam intersubjetivas, ainda que num sentido não tão forte como a de Honneth. De toda forma, deixo claro que trabalho aqui com uma concepção mais ampla e menos ortodoxa de intersubjetividade.

A segunda ideia, daí decorrente, é a ênfase que essas teorias póem na dimensão normativa, seja na necessidade, por exemplo, de que precisamos "viver juntos" e de que é possível "se opor sem se massacrar”, segundo a formulação de Alain Caillé, seja na ênfase dada a noções como justiça, democracia e emancipação (II). Entendo também que crítica imanente e normatividade são características intrínsecas das teorias críticas. Se a primeira é o método privilegiado de análise, a segunda sugere a possibilidade de um mundo diferente e melhor do que o atual. No entanto, é da crítica imanente do presente que deve emergir o horizonte emancipatório de um mundo melhor. Por isso, as duas se completam, o que não quer dizer que elas, muitas vezes, não apareçam separadas, como em situações nas quais uma determinada teoria é criticada por padecer de déficit normativo, como, por exemplo, a crítica de Jürgen Habermas à teoria do poder de Foucault (Habermas, 1987); ou, alternativamente, por postular uma sociedade futura melhor que não decorre necessariamente da crítica do presente, mas de uma imagem do futuro construída a partir de uma crítica apenas externa, como a que Friedrich Engels atribuiu aos chamados socialistas utópicos (Engels, 1975). Ressalto que quando falo neste texto em virada normativa nos debates social-científicos quero chamar a 
atenção tanto para a crescente recorrência ao termo crítica por parte dos autores ao definirem suas próprias teorias quanto para o aumento da frequência nos debates de termos com claro apelo normativo.

Em terceiro lugar, pode-se perceber também que politicamente essas teorias, mesmo quando recorrem à palavra "socialismo", tendem a enfatizar caminhos para a mudança social que evitem extremismos de direita e de esquerda, assim como de qualquer tipo de fundamentalismo, o que nos permite denominá-las perspectivas de "via média" (III). E ao falar em "via média” quero realçar que, nos autores aqui discutidos, a ideia de emancipação está geralmente associada com os termos justiça, democracia e socialismo, embora com importantes diferenças entre os autores tanto nas formas como concebem cada um dos termos quanto na ênfase que neles colocam. Em todos, porém, democracia parece ser a palavra-chave para se formular concepçóes de justiça e de socialismo, a despeito das muitas diferenças em como a concebem. Da mesma forma, democracia relaciona-se tanto à ideia de intersubjetividade, já que envolve a participação dos envolvidos na própria definição do que e como deve ser feito, quanto ao papel central dos movimentos sociais, cujas lutas por emancipação são muitas vezes conflitantes entre si e, por isso, são objeto de constante negociação entre os envolvidos.

Por fim, para lidar com essas três ideias ou hipóteses, parto de uma releitura ou apropriação crítica do conceito de "reformas revolucionárias", elaborado por André Gorz na década de 1960 para escapar da dicotomia entre reforma e revolução. Embora Gorz o tenha elaborado tendo em vista uma situação específica, creio que o conceito pode ser generalizado para se analisar temas não abordados na formulação original. É com base numa releitura desse conceito, portanto, que pretendo avaliar o potencial crítico de algumas dessas teorias contemporâneas (IV).

\section{I}

Todos os quatro autores aqui tratados, de alguma forma, apresentam suas respectivas teorias como um paradigma intersubjetivo que se distancia tanto das abordagens holistas quanto das individua- listas. A esse respeito, Alain Caillé, por exemplo, é bastante explícito quando define sua teoria da dádiva, inspirada em Marcel Mauss, como um "terceiro paradigma" antiutilitarista (Caillé, 2000); ou ainda, mais recentemente, ao falar de sociabilidades primária e secundária no paradigma da dádiva (Caillé, 2014) e também quando formula as bases de um manifesto convivialista, guiado pela expressão "se opor sem se massacrar" como a base de uma convivência democrática adequada ao mundo atual (Caillé, 2011; 2014). Os outros três autores também são muito claros quando à natureza intersubjetivista de seus empreendimentos teóricos (Honneth, 2003a; Fraser, 1989 e 1997; Santos, 2007).

Vejamos. Mais diretamente vinculada à tradição frankfurtiana, de Horkheimer a Habermas, a teoria do reconhecimento de Axel Honneth é intrinsecamente intersubjetiva, e tem, em sua própria constituição, como as principais referências teóricas, autores que também postulam uma abordagem intersubjetivista, como Georg Hegel, George Herbert Mead, Donald Winnicott e Jürgen Habermas; na verdade, a relação de Honneth com as teorias deles pode ser definida como de apropriação crítica (Honneth, 2003a; 2003b; 2012). A despeito de manter distanciamento crítico em relação a Habermas, por exemplo, a teoria de Nancy Fraser, como as outras, situa-se claramente desde o início nessa tradição intersubjetivista, seja no âmbito teórico-epistemológico, quando questiona a ausência de "gênero" na teoria de Habermas, seja no âmbito político-normativo, quando propõe uma releitura crítica do discurso sobre as "necessidades”, ou ainda quando, mais recentemente, propóe um modelo de paridade de participação como categoria unificadora de sua teoria da justiça (Fraser, 1989; 2003; 2009a). ${ }^{6}$

O mesmo pode-se dizer em relação a Boaventura de Sousa Santos, cuja principal crítica ao que denomina "pensamento abissal", eurocentrista e colonizador está justamente no "desperdício de experiência”, motivado grandemente pela exclusão do outro, cujo reconhecimento deveria ser a base de um diálogo intersubjetivo relevante (Santos, 2001; 2006; 2007; 2010). Daí, no centro de sua proposição de uma teoria crítica pós-moderna está a ideia de que todo conhecimento crítico deve começar 
pela própria crítica do conhecimento: "A teoria crítica pós-moderna constrói-se a partir de uma tradição epistemológica marginalizada e desacreditada da modernidade, o conhecimento-emancipação. Nesta forma de conhecimento, conhecer é reconhecer, é progredir no sentido de elevar o outro da condição de objeto à condição de sujeito" (Santos, 1999, p. 205).

Ao mesmo tempo, todos eles também apresentam suas respectivas teorias como teorias gerais capazes de lidar com a sociedade como um todo, o que fica evidente nos diagnósticos de época encontrados nos escritos de cada um deles; isso a despeito de alguns contestarem a noção de grande teoria (Caillé, 1986: Santos, 2007). Aliás, a intenção de cada um ou uma de apresentar sua própria teoria como uma teoria crítica, já supóe, a meu ver, a ambição de síntese teórica.

Isso vale, sobretudo, para a teoria do reconhecimento de Honneth, cujo monismo moral aparece como um pano de fundo unificador, capaz de, segundo ele próprio, lidar com o todo da sociedade capitalista moderna, entendida como uma ordem de reconhecimento (Honneth, 2001a; 2003a; 2003b). A propósito, à semelhança do sistema de vida ética de Hegel (1967, p. 105-223), as três formas de reconhecimento (amor, direitos e solidariedade) constituem o núcleo de um modelo que deveria ser capaz de apreender o conjunto da sociedade, em suas várias dimensóes: econômica, política e cultural. Por outro lado, são também visíveis os esforços empreendidos por Honneth, desde seu Luta por reconhecimento, para responder aos críticos que não veem toda essa abrangência em sua teoria (Honneth, 2001a; 2003b; 2007; 2014). ${ }^{7}$ Nesse mesmo sentido, a introduçáo escrita em conjunto com Nancy Fraser para o livro em que os dois polemizam deixa bem claro que ambos postulam uma teoria crítica da sociedade capitalista; uma teoria que seja capaz de lidar com a totalidade da sociedade:

Deve o capitalismo, como existe hoje, ser compreendido como um sistema social que diferencia uma ordem econômica não diretamente regulada por padróes institucionalizados de valor cultural de outras ordens sociais que o são? Ou deve a ordem econômica capitalista ser entendida como uma consequência de um modo de avaliação cultural que está conectado, desde o início, a formas assimétricas de reconhecimento? (Fraser e Honneth, 2003, p. 5). ${ }^{8}$

Como se vê, a teoria de Nancy Fraser também tem a mesma ambição. A propósito, seu modelo teórico tripartite, que tem como articulador a noção de "paridade de participação", é formado pelas categorias reconhecimento, redistribuição e representação;' categorias que, para ela, referem-se, respectivamente, às dimensôes cultural, econômica e política da sociedade (Fraser, 2003a; 2011; 2013). $\mathrm{Na}$ formulação de Fraser, no entanto, a noção de reconhecimento, entendido como status, é diferente daquela postulada por Honneth (2001c), seja porque se refere apenas ao âmbito sociocultural, seja porque é mais restrita que a do autor alemão que entende reconhecimento como uma categoria moral abrangente (Fraser, 2000; Fraser e Honneth, 2003; Honneth, 2001a).

Alain Caillé, cuja teoria da dádiva é elaborada a partir de uma reapropriação das formulaçóes de Marcel Mauss em seu "Ensaio sobre a dádiva" (Mauss, 2003, pp. 185-314), entende a dádiva (don, em francês) como um fato social total, cujo circuito - dar, receber, restituir - envolve o social como um todo, caracterizando-se, assim, como um modelo sintético, também tripartite como os outros vistos até agora. Na verdade, Caillé, para quem a dádiva é uma forma de "reconhecimento agonístico” (Caillé, 2003, pp. 5-28; 2009, pp. 149-168), ao comentar o debate recente sobre reconhecimento, refere-se a este último como "novo fenômeno social total" (Caillé, 2007).

A despeito de ser um crítico da ideia de totalidade e das teorias que ambicionam explicar o conjunto das relaçôes sociais, Boaventura de Sousa Santos também apresenta uma teoria - denominada Epistemologia do Sul ou Ecologia dos Saberes cuja ambição de abrangência talvez seja até maior que as das outras três. Da mesma forma que os outros autores, sua teoria se presta a ser apresentada como um modelo tripartite, que envolve as dimensôes epistemológica, teórica e política; ou seja, ambiciona explicar a sociedade como um todo, embora se recuse a apresentá-la como uma "grande teoria", 
de um único autor. Isso fica claro quando apresenta suas formulaçóes como uma "ecologia dos saberes", já que nega à ciência moderna o monopólio das explicaçóes válidas (Santos, 2006; 2007; 2010). Esse monopólio explicativo reivindicado pela ciência moderna representa, segundo Santos, por um lado, uma espécie de colonialismo epistemológico e, por outro, um desperdício de experiência, que reduz a compreensão do mundo a uma compreensão europeia do mundo; ou seja, para ele, trata-se na verdade de reducionismo e particularismo sob a capa de totalidade e universalidade.

Santos, para quem "o conhecimento totalizante é um conhecimento da ordem sobre o caos", afirma que o que distingue a sociologia funcionalista da sociologia crítica é o fato de uma pretender a "ordem da regulação social", enquanto a outra pretende a "ordem da emancipação social” (Santos, 1999, p. 205); mas, acrescenta ele, na virada para o século XXI, encontramo-nos perante a desordem de ambas. Daí a dificuldade de se construir atualmente uma teoria crítica com base nos pressupostos da modernidade, como os do conhecimento-regulação, no qual ignorância é igual a caos e saber é igual a ordem; ou do conhecimento-emancipação, em que ignorância equivale a colonialismo e saber a solidariedade. Para Santos, "ao negligenciar a crítica epistemológica da ciência moderna, a teoria crítica, apesar de pretender ser uma forma de conhecimento-emancipação, acabou por se converter em conhecimento-regulação" (Idem, ibidem). ${ }^{10}$

Nesse sentido, sua Ecologia dos Saberes, ou Epistemologia do Sul, emerge como um contraponto crítico ao que chama "razão indolente", preguiçosa, que se apresenta de duas formas: como uma "razão metonímica", que toma a parte pelo todo e utiliza um conceito restrito de totalidade, e como "razão proléptica", baseada numa concepção linear de tempo, segundo a qual já sabemos qual é o futuro: "o progresso, o desenvolvimento do que temos" (Santos, 2007, p. 26).

Como teorias críticas, por outro lado, a maneira como cada uma delas lida com a relação entre teoria e prática faz com que elas também se distanciem das abordagens positivistas, ou daquilo que Horkheimer (1983) denominava teoria tradicional, cuja separação entre sujeito e objeto abre caminho para uma suposta neutralidade científica. Ao contrário dessas últimas, as teorias críticas aqui discutidas lidam com a relação sujeito/objeto de forma a não partilhar a ilusão de que os interesses dos cientistas (sujeitos) possam ser totalmente abstraídos da realidade (objeto) por eles analisada, permitindo-lhes uma atitude de neutralidade perante o objeto; ou seja, permitindo uma separação entre teoria e prática. $\mathrm{Na}$ trilha de toda a tradição crítica, as teorias dos quatro autores aqui discutidos, a despeito de suas diferenças, mostram claramente que teoria e prática estão imbricadas de maneira que não se pode separar de forma estanque o sujeito que analisa do objeto em análise (Honneth, 1994; Fraser, 1989b; Caillé, 1986; Santos, 2007). Tudo isso, portanto, afasta-os das formulaçóes teóricas que se apoiam nos modelos das ciências naturais; mas, ao mesmo tempo, não significa, para nenhum deles, uma aposta no relativismo.

\section{II}

Os quatro autores aqui discutidos deixam claro que suas teorias são teorias críticas. Mesmo Alain Caillé, o que menos referência faz à tradição da teoria crítica frankfurtiana, situa-se numa tradição crítica, conforme indica claramente o título de seu livro Critique de raison utilitaire: manifeste $d u$ Mauss, de 1989. Esse título sugere pelo menos duas coisas. Uma: é o projeto de criticar o utilitarismo, ou a razão utilitária, conforme o título indica. $\mathrm{Ou}$ tra: é a criação, já que se trata de um manifesto, do Movimento Antiutilitarista nas Ciências Sociais (MAUSS na sigla em francês e, ao mesmo tempo, uma espécie de homenagem a Marcel Mauss, autor do mencionado "Ensaio sobre a dádiva", no qual o movimento se inspira). Aliás, Caillé foi criador e é impulsionador desse movimento antiutilitarista, criado na França no início da década de $1980 .{ }^{11}$

Já Axel Honneth, ao contrário de Caillé, é intimamente ligado à tradição da teoria crítica frankfurtiana e considerado um de seus herdeiros e continuadores, pois ocupa o mesmo lugar (intelectual e institucional) ocupado antes por Horkheimer, Adorno e Habermas, autores da primeira e da segunda geração dessa vertente de pensamento. Aliás, Honneth é até mesmo 
considerado o principal representante da terceira geração dessa vertente de teóricos frankfurtianos, o que seus escritos não desmentem, seja pelo escopo de sua obra, seja pelas referências explícitas a essa tradição de pensamento. Reconhecido internacionalmente como um dos principais teóricos contemporâneos no campo da teoria social, Honneth nunca negou sua intenção de continuar, com uma teoria própria que parte de uma reapropriação critica das teorias de seus antecessores, o empreendimento iniciado por Horkheimer e Adorno e continuado por Habermas (2012). Além de seu livro Crítica do poder (Honneth, 1991), no qual apresenta criticamente as teorias de seus antecessores, há outro texto - base de sua aula inaugural na Universidade Livre de Berlim, em 1993 - no qual ele indica claramente, já no título, sua intenção de continuar aquele empreendimento: "A dinâmica social do desrespeito: sobre o lugar da teoria crítica hoje" (Honneth, 1994).

No que se refere a Nancy Fraser, sua relação com a tradição crítica é antiga (Fraser, 1980) e, embora não se possa afirmar que ela tenha o mesmo vínculo orgânico que Honneth com aquela tradição da teoria crítica frankfurtiana, esta última não deixa de ser uma de suas principais inspiraçóes teóricas, como fica claro já em seu primeiro livro, Unruly practices, de 1989. Em dois dos textos que compóem essa obra, há referências claras a seu objetivo de elaborar uma teoria crítica, ainda que seja uma "teoria crítica socialista-feminista", conforme o subtítulo de um deles (Fraser, 1989, pp.161-187). Isso se dá igualmente com outro de seus textos, cujo título é "What's critical about critical theory? The case of Habermas and Gender" (Fraser, 1989, pp. 113-143), em que ela desenvolve uma interessante crítica à teoria crítica de Habermas, por esta última silenciar sobre a questão de gênero. ${ }^{12}$ Nos dois casos, a intenção de construir uma teoria crítica é bastante clara; claro também, para ela, é que uma teoria crítica que se preze não deve passar ao largo da questão de gênero, tema recorrente em sua produção teórica posterior (Fraser, 1997; 2003a; 2009a; 2009b; 2011; 2013).

Quanto a Boaventura de Sousa Santos, a intenção crítica de seu empreendimento teórico é bem evidente, conforme suas próprias palavras:
Por teoria crítica entendo toda a teoria que não reduz a "realidade" ao que existe. A realidade, qualquer que seja o modo como é concebida, é considerada pela teoria crítica como um campo de possibilidades e a tarefa da teoria consiste precisamente em definir e avaliar a natureza e o âmbito das alternativas ao que está empiricamente dado. A análise crítica do que existe assenta no pressuposto de que a existência não esgota as possibilidades da existência e que, portanto, há alternativas suscetíveis de superar o que é criticável no que existe. O desconforto, o inconformismo ou a indignação perante o que existe suscitam o impulso para teorizar a sua superação (Santos, 1999, p. 197).

E a despeito de sua crítica às vertentes teóricas europeias e norte-americanas, base do que ele denomina pensamento abissal, Santos também faz referência explícita à tradição frankfurtiana, em especial a Horkheimer, a quem atribui a melhor definição de teoria crítica moderna: "Horkheimer definiu-a melhor que ninguém. Segundo ele, a teoria crítica moderna é, antes de mais, uma teoria fundada epistemologicamente na necessidade de superar o dualismo burguês entre o cientista individual produtor autônomo de conhecimento e a totalidade da atividade social que o rodeia” (Santos, 1999, p. 199). Mas Santos deixa claro que, embora a considere parte do que chama conhecimento-emancipação, que ele contrapóe ao conhecimento-regulação das teorias não críticas, ele vê limites nessa teoria crítica moderna; pois, em seu entendimento, ela acabou por ser dominada pela segunda forma de conhecimento, tornando-se também parte do que ele denomina pensamento abissal. Por isso, ele postula uma teoria crítica pós-moderna, baseada numa "ecologia dos saberes" ou "epistemologia do Sul", que seja capaz de superar essas limitações, expressas pelas duas já referidas formas de "razão indolente", a metonímica (que toma a parte pelo todo) e a proléptica (cuja visão de futuro funda-se apenas numa concepção de tempo linear) (Santos, 2007).

Ao considerarem seus empreendimentos teorias críticas, os quatro autores enfatizam bastante a dimensão normativa de suas teorias, apelando para noçôes como emancipação, autonomia, autodeter- 
minação, direitos humanos, justiça, democracia e mesmo socialismo (Fraser, 1989; 2001; Caillé, 2011 a; Santos, 2011; Honneth, 2015). A despeito de diferenças na compreensão de cada uma dessas categorias pelos autores aqui discutidos, elas de alguma forma aparecem nos escritos de todos eles, mesmo que a ênfase dada a cada uma delas possa variar de um autor para outro.

A teoria de reconhecimento de Axel Honneth emerge, já em seu início, como uma proposta de substituir a teoria da emancipaçáo baseada no paradigma do trabalho, conforme ocorre no marxismo tradicional, ${ }^{13}$ por uma teoria da emancipação baseada no paradigma do reconhecimento (Honneth, 1995, pp. 3-14), projeto que ele tem perseguido desde então. Pode-se dizer, ainda, que as noçóes de autonomia e autorrealização têm lugar de destaque nessa teoria do reconhecimento, assim como a de democracia "como cooperação reflexiva", inspirada em John Dewey (Honneth, 2012; 2001b). Em diversos trabalhos recentes, por outro lado, ele tem realçado bastante a relação entre reconhecimento e justiça (Honneth, 2003b; 2004; 2012), encontrando mesmo alguma proximidade entre sua teoria do reconhecimento e a teoria da justiça formulada por David Miller (1976; 1999).

Justiça e democracia são temas caros também a Nancy Fraser, cuja polêmica com Axel Honneth gira em torno de como melhor formular uma teoria da justiça capaz de lidar com os problemas do mundo contemporâneo, em especial o tema do livro conjunto, que é a relação entre reconhecimento e redistribuição (Fraser e Honneth, 2003). Esse debate, pelo menos em relação a Fraser, tem como pano de fundo a relação tensa entre igualdade e diferença, ambas importantes categorias de sua teoria de justiça (Silva, 2008, pp. 93-110). ${ }^{14}$ No que concerne ao tema da democracia, é bom lembrar que "representação" é uma das três categorias formadoras de sua teoria de justiça centrada na noçáo de paridade de participação (Fraser, 2003a; 2009; 2011).

A teoria de Alain Caillé também lida com os temas do reconhecimento, como já mencionei, assim como com o da justiça. O paradigma da dádiva, porém, procura desenvolver uma noção de reconhecimento como gratidão que mantém certa distância crítica em relação à noção de justiça como equivalência (Caillé, 2003; 2006; 2008). ${ }^{15} \mathrm{E}$, embora a partir de um registro um pouco diferente, ele intervém na discussão sobre redistribuição, quando fala em renda de cidadania incondicional (Caillé, 2000, pp. 93-120). Crítico das ciências sociais que se desengajam de preocupações políticas (Caillé, 1993), ele coloca a dimensão política no centro de sua teorização. Por isso, da mesma forma que a renda de cidadania, a noção de democracia está no cerne de sua proposição a respeito do convivialismo (Caillé, 2011; 2013; 2014).

No caso de Boaventura de Sousa Santos, a preocupação que parece animá-lo é justamente elaborar uma teoria da emancipação, libertada das restriçóes eurocêntricas presentes no chamado pensamento abissal. E nessa teoria da emancipação, denominada Epistemologia do Sul ou Ecologia dos Saberes, temas como reconhecimento, redistribuição, cidadania, direitos humanos, justiça, igualdade, diferença e democracia são partes constitutivas (Santos, 2001; 2006; 2007; 2010). Mas, diferente das outras três, a teoria de Santos dedica um grande esforço para se construir como uma alternativa às teorias elaboradas no Atlântico Norte; e, nesse sentido, a despeito de se inspirar em algumas tradiçóes também do Norte (Santos, 2010a), sua abordagem pode ser vista, em grande medida, como um contraponto crítico às outras três aqui discutidas.

\section{III}

Em termos de proposiçóes para mudança social, pode-se dizer que politicamente as quatro teorias procuram caminhos ou perspectivas que se distanciem de soluçóes extremistas ou fundamentalistas, mesmo quando falam em socialismo. Ou seja, se há um horizonte utópico a ser buscado por cada uma dessas teorias, ele não se confunde com a tradicional ideia de revolução professada pelo marxismo clássico, embora elas também não pareçam se contentar com o atual estado das coisas. Embora haja diferenças no que cada um desses autores entende por justiça e por democracia, esses conceitos são os que melhor traduzem, para eles, os objetivos emancipatórios de uma sociedade melhor, mais justa. 
A propósito, em um texto no qual oferece um "esboço de uma teoria plural de justiça”, Axel Honneth faz, logo no início, a seguinte afirmação:

Até fins da década de 1980, o domínio do marxismo na Europa e a ampla influência de Rawls nos Estados Unidos asseguraram o princípio norteador de uma teoria normativa da ordem política. A despeito de diferenças nos detalhes, havia acordo quanto à eliminação de desigualdades social e econômica que não pudessem ser justificadas com argumentos razoáveis. Faz algum tempo, essa influente ideia de justiça, que pode ser entendida politicamente como uma expressão da época social democrática, parece ter sido substituída por uma nova ideia: a de que não é mais a eliminaçáo de desigualdade que parece representar o objetivo normativo, mas a anulação de humilhação ou desrespeito; "distribuição igual" ou "igualdade de bens" não são mais suas categorias centrais, mas "dignidade" ou "respeito" (Honneth, 2004, p. 351).

O texto supracitdo contém um diagnóstico de época e, ao mesmo tempo, uma justificativa para Honneth vincular justiça e reconhecimento, que é o objetivo principal não só do citado artigo, mas de sua teoria num sentido mais geral (Honneth, 2014). Na verdade, o diagnóstico serve como referência para ele mencionar criticamente sua interlocutora e concorrente Nancy Fraser. Ela faz um diagnóstico semelhante, mas postula uma teoria bidimensional de justiça que pretende articular reconhecimento e redistribuição como instâncias não redutíveis de justiça, conforme os dois debatem em livro conjunto (Fraser e Honneth, 2003). ${ }^{16}$ De fato, Honneth se refere a duas interpretaçóes alternativas que partem do mesmo diagnóstico: a de Fraser, fundada na irredutibilidade de reconhecimento e redistribuição, da qual ele discorda; e a dele próprio, que toma o reconhecimento como uma categoria moral abrangente, capaz de lidar também com problemas de distribuição ou redistribuição.

Assim entendido, reconhecimento torna-se a base de uma teoria da justiça na qual "a experiência de injustiça é sempre medida em termos de impedimento de algum reconhecimento considerado legítimo"; e, por outro lado, "o estabelecimento da ordem social capitalista liberal deve ser descrita como um processo de diferenciação em três esferas de reconhecimento" (Honneth, 2004, p. 353), que são, conforme sua tipologia, amor, direitos e solidariedade.

A ligação entre justiça e democracia, por sua vez, parece clara na seguinte reflexão de Honneth sobre os fundamentos normativos do Estado de bem-estar:

A concessão de direitos sociais [...] é medida primeiramente de acordo com a ideia de proporcionar a todo membro de uma sociedade a medida de reconhecimento social que o torna um cidadão completo. Se, além disso, considerarmos que tal reconhecimento também contém a incorporação do cidadão no processo de cooperação social, a conclusão resultante é que programas de salvaguarda econômica mínima não são suficientes; antes, o Estado de bem-estar está então sujeito ao requerimento de que a todo indivíduo seja dada a chance de participar de maneira elementar no contexto cooperativo da sociedade dando sua própria contribuição. É apenas então [...] que todo indivíduo está numa posição de apreender seu "Eu" como um membro completo de uma sociedade (Honneth, 2004, p. 302).

Essa teoria da justiça liga-se, portanto, a uma concepção de "democracia como cooperação reflexiva”, apresentada como um terceiro modelo de democracia, diferente do republicano e do procedimental. Trata-se, nas palavras de Honneth, de um modelo que combina "deliberação racional e comunidade democrática”, assim definido por ele: "Esse modelo - de forma bem resumida - encara a ideia normativa de democracia não só como um ideal político, mas primeiramente como um ideal social" (Honneth, 2001b, pp. 67 e 91). Por fim, tudo isso é contemplado por sua tipologia do reconhecimento, a cujas três formas de reconhecimento (amor, direitos e solidariedade) vinculam-se três modos de autorrelação prática positiva, expressos, respectivamente, pelas noçóes de autoconfiança, autorrespeito e autoestima, indicadas como manifestaçóes de autorrealização dos indivíduos (Honneth, 2003a).

Nancy Fraser, por seu turno, propóe-se a desenvolver uma teoria dualista da justiça, que trata reconhecimento e redistribuição como categorias irredu- 
tíveis; dualismo que ela sustenta ser analítico e não substantivo. Da mesma forma que Honneth, Fraser faz um diagnóstico de época. Em seu diagnóstico, porém, ela afirma que "o discurso da justiça, uma vez centrado na distribuição, está agora dividido entre reivindicações por redistribuição e reivindicações por reconhecimento, com o último tendendo a predominar" (Idem, p. 7). Com as reivindicaçóes de justiça tornando-se crescentemente divididas entre aquelas "que buscam uma distribuição mais justa de recursos e riqueza" e aquelas que reivindicam justiça social na forma de reconhecimento da diferença, Fraser vê a necessidade de uma teoria que seja capaz de lidar com as duas formas de justiça, sem reduzir uma à outra. Sua tese, segundo a própria autora, evita as falsas antíteses entre política de classe e política de identidade ou entre social democracia e multiculturalismo, sendo assim descrita:

Justiça hoje requer ambos redistribuição e reconhecimento. Nenhuma das duas reivindicaçóes sozinha é suficiente. O problema é como combinar as duas. Os aspectos emancipatórios das duas problemáticas devem ser integrados num único quadro abrangente. Teoricamente, a tarefa é divisar uma concepção bidimensional de justiça que possa acomodar ambas as reivindicações "defensáveis" por igualdade social e por reconhecimento da diferença. Em termos práticos, a tarefa é divisar uma orientação política programática que possa integrar o melhor da política de redistribuição com o melhor da política do reconhecimento (Idem, p. 9).

A partir desta tese geral, Fraser propóe uma abordagem denominada dualismo perspectivo que, segundo ela, seria capaz de assumir tanto o ponto de vista da redistribuição quanto o do reconhecimento, "sem reduzir nenhuma dessas duas perspectivas à outra, como perspectivas analíticas" (Idem, p. 70). Articulada pela noção de paridade de participação, essa teoria dualista da justiça seria traduzida, em termos práticos, pela institucionalização de uma justiça democrática, que ela define como uma "via média" de reformas não reformistas: "reformas que parecem ser afirmativas em abstrato", mas que "podem ter efeitos transformativos em alguns contextos” (Idem, p. 78).
A esse propósito, a distinção que ela faz entre afirmação e transformação, quando trata das medidas utilizadas para corrigir injustiças, é bastante ilustrativa:

Por remédios afirmativos para injustiça entendem-se remédios voltados para a correção de resultados indesejáveis de arranjos sociais sem perturbar o arcabouço que os gera. Por remédios transformativos, em contraste, entendem-se remédios orientados para a correção de resultados indesejáveis precisamente pela reestruturação do arcabouço genérico que os produz. O ponto crucial do contraste é a relação entre os resultados oferecidos pelo Estado versus os processos que os produzem (Fraser, 2001, pp. 265-266).

Assim, no âmbito da redistribuição, entre os exemplos concretos que ela nos dá de reforma não reformista está a renda básica incondicional (Silva, 2014).

Por fim, ela afirma que, em termos políticos, uma estratégia de reformas não reformista é uma maneira de pensar a mudança institucional, permitindo vislumbrar a possibilidade de corrigir má distribuição e ausência de reconhecimento. Mas para essa estratégia de reforma se tornar viável, parece imprescindível a terceira noção de seu modelo: a dimensão política da representação. Com esta última, o modelo passa a contemplar as dimensóes econômica, cultural e política da sociedade.

Alain Caillé, cujas formulaçóes baseiam-se no modelo tripartite da dádiva, tem mantido uma interessante interlocução com o debate sobre reconhecimento. Ele é também o idealizador de um "manifesto convivialista" (mais tarde assinado, entre outros, por Axel Honneth), que expressa muito bem sua proposição para a mudança social (Caillé, 2011; 2012). O manifesto é apresentado como uma espécie de programa mínimo para se enfrentar as ameaças do presente, cujo diagnóstico de época indica que são de ordem moral, política, ecológica ou econômica; ele também é visto como capaz de fornecer as bases de uma existência comum, traduzida pela expressão-chave: "se opor sem se massacrar". Como expressão geral da necessidade de "vivermos juntos" ou como forma política para guiar 
a solução de conflitos entre e intragrupos humanos, o manifesto parece politicamente muito sábio; no âmbito teórico, por outro lado, ele também é relevante por expressar uma perspectiva intersubjetivista, fundada no paradigma da dádiva; este último, como se sabe, procura ir além dos reducionismos individualista e holista, ao propor a perspectiva da dádiva como um terceiro paradigma alternativo (Caillé, 2012; 2014).

Uma apreciação desse manifesto me permite inferir algumas conclusóes. A primeira delas é que ele expressa uma concepção, ou modelo, de democracia fundada nas ideias de associação e cooperação como contraponto a noçóes de democracia que priorizam o mercado ou o Estado como ponto de apoio principal. Nisso percebe-se semelhança com o modelo de democracia proposto por Honneth. A segunda conclusão é que o manifesto postula uma concepção de desenvolvimento estacionário que prioriza a dimensão qualitativa em relação à quantitativa, no qual seja possível pensar uma relação mais amigável com a natureza (preocupação ecológica com o futuro do planeta) e também uma relação de autolimitação em relação ao consumo, que precisa ser refreado por estar intrinsecamente ligado tanto ao crescimento que destrói, sem repor, os recursos naturais quanto à poluição ambiental. Esse tema é pouco teorizado pelos outros autores, com exceção, talvez, de Boaventura de Sousa Santos.

A terceira conclusão é que democracia associativa e desenvolvimento estacionário se completam com uma concepção de riqueza que priorize o "ser" em relação ao "ter", aproximando-o da ideia honnethiana de reconhecimento; para isso, no entanto, é necessário fixar limites tanto para a pobreza extrema quanto para a riqueza extrema: primeiro com o estabelecimento de uma renda mínima que permita aos mais pobres viver com dignidade; segundo, que também se estabeleça limites para a renda máxima, de forma a não permitir que algumas pessoas acumulem riqueza além de um patamar razoável. Essas são medidas de uma política distributiva que contribuiria para reduzir a distância entre ricos e pobres. Não dá para não pensar aqui na semelhança com a noção de redistribuição de Nancy Fraser. Alain Caillé entende que essas são condiçôes que permitiriam "vivermos juntos" de forma mais digna e melhor, democraticamente, respeitando e valorizando a diversidade, e abrindo caminho para um novo universalismo ou, mais propriamente, pluriversalismo (Caillé, 2011; 2012; 2014).

Boaventura de Sousa Santos, que também participa no debate sobre reconhecimento e redistribuição (Santos, 2001; 2006), é, assim como Alain Caillé, um adepto da prática de manifestos. No entendimento de Santos, aliás, os objetivos comuns dos movimentos sociais "só se tornam princípios de ação graças às práticas de manifesto”, desde que elas contenham "programas claros e inequívocos de alianças baseadas em denominadores comuns que são mobilizadores porque produzem uma soma positiva" (Santos, 2006, p. 198). Defensor de uma Epistemologia do Sul, ponto de partida para um programa teórico e político contra-hegemônico, ele também defende a tese de que não é possível justiça social global sem justiça cognitiva global: "Não é possível hoje uma epistemologia geral, não é possível hoje uma teoria geral. A diversidade do mundo é inesgotável, não há teoria geral que possa organizar toda essa realidade... Não é possível, e tampouco desejável, mas necessitamos de uma teoria sobre a impossibilidade de uma teoria geral" (Santos, 2007, p. 39).

A partir dessa Epistemologia do Sul, a qual inclui uma sociologia das ausências ${ }^{17}$ e uma sociologia das emergências, ${ }^{18}$ surge a perspectiva de uma política emancipatória, contra-hegemônica, capaz de lidar com os desafios do presente. Um desses desafios é a própria reinvenção do pensamento emancipador. Mas eles também dizem respeito às questóes de justiça e democracia. Ou seja, uma concepção de justiça que traga para o centro da cena as formas invisíveis de opressão e seja capaz de lidar, conforme o caso, com os problemas de igualdade e de diferença; e também uma democracia de alta intensidade que possa viabilizar "a articulação entre democracia participativa e democracia representativa” (Idem, p. 96), evitando o fundamentalismo de uma e impedindo que a outra se restrinja um mero mercado político.

Para que isso seja possível, no entanto, é preciso lidar com outro conjunto de problemas, que são as relações "entre Estado e movimentos sociais; entre partidos e movimentos sociais; e entre 
movimentos sociais entre si" (Idem, p. 93). Segundo Santos, os caminhos para tanto sáo complexos, já que existem os fundamentalismos a serem evitados: o dos partidos, que se apoiam na democracia representativa, contra os movimentos sociais, que são mais afeitos à democracia participativa; e o fundamentalismo dos movimentos sociais contra os partidos políticos, pela razão inversa. Há também a necessidade de contornar a diversidade dos movimentos sociais, com suas pautas e reivindicaçôes específicas, para a qual ele propóe o conceito de pluralidades despolarizadas, conforme a seguinte definição: "o lado político de uma epistemologia dos saberes é a incompletude de propostas políticas e a necessidade de uni-las sem uma teoria geral" (Idem, p. 101).

\section{IV}

Seria possível no interior do capitalismo - isto é, sem havê-lo previamente demolido - impor soluçōes anticapitalistas que não sejam logo incorporadas e subordinadas ao sistema? É a velha pergunta sobre "reforma e revolução". Era (ou é) primordial quando o movimento tinha (ou tem) escolha entre a luta por reformas ou a insurreição armada. Este não é mais o caso na Europa ocidental. Eis por que a pergunta não mais possui a forma de uma alternativa: refere-se apenas à possibilidade de "reformas revolucionárias", isto é, reformas que se encaminham no sentido de uma transformaçáo radical da sociedade (Gorz, 1968, p. 12).

É com esse texto que André Gorz introduz, no início da década de 1960 , o tema das reformas revolucionárias como um conceito mediador capaz de superar a alternativa, considerada então insustentável, entre reforma e revolução. ${ }^{19}$ Para ele, era preciso deixar de lado a ideia equivocada de que toda reforma seria necessariamente reformista. Mas, por considerar que não é nítida a linha que separa uma reforma reformista de uma reforma revolucionária ou não reformista, ele se propóe a esclarecer a distinção entre as duas. Assim, para Gorz, "reformista é uma reforma que subordina seus objetivos aos critérios de racionalismo e possibilidade de um sistema e de uma política dados. O reformismo afasta de vez os objetivos e as reivindicaçóes [...] incompatíveis com a conservação do sistema" (Idem, p. 13). Enfim, uma reforma reformista é aquela que mantém intacta a estrutura do sistema econômico e político vigente.

Por outro lado, a propósito do que consiste em uma reforma revolucionária, ou não reformista, ele escreve o seguinte:

Não é necessariamente reformista uma reforma reivindicada não em função do que é possível no quadro de um sistema e de uma gestáo dados, mas do que deve ser tornado possivel em função das necessidades e das exigências humanas... $\mathrm{O}$ que é próprio de uma luta por reformas não reformistas - por reformas anticapitalistas - é que esta luta não faz depender, de critérios capitalistas de racionalidade, a validade e o direito tradicionalmente consagrado das necessidades. Ela não se determina em função do que pode ser, mas do que deve ser (Idem, ibidem).

Essa definição foi elaborada por Gorz no contexto europeu da década de 1960 , tendo em vista as lutas do movimento de trabalhadores de entáo, como indica o título de seu livro Estratégia operária e neocapitalismo, publicado em 1964. Mas ele retornou ao tema mais recentemente, em livros como Misérias do presente, riqueza do possivel, de 1997 (Gorz, 2004, pp. 85-125). O fato de retomar o tema das reformas revolucionárias em livros mais recentes torna-se interessante inclusive porque permite uma maior aproximaçáo com temas abordados também pelos quatro autores aqui discutidos, já que tratam de um mesmo contexto histórico e, quiçá, geográfico.

Ora, naquele contexto dos anos de 1960, a discussão do tema das reformas revolucionárias estava conectada com uma estratégia de luta dos trabalhadores, em especial os operários de fábrica; ou seja, tratava-se de vinculá-la a uma estratégia da classe operária, tida entáo, por muitos, como o principal sujeito da almejada transformação social anticapitalista. As reivindicaçóes em pauta estavam, pois, em 
grande medida relacionadas à questão do poder operário na fábrica e no sistema produtivo. Isso tornava necessário avaliar também a alternativa entre poder subordinado e poder autônomo, conforme a definição dada a seguir. A primeira forma de poder subordinado - traduzia uma situação na qual os trabalhadores participam de uma política e de uma gestão econômica no âmbito dos resultados e da execução, mas não no âmbito das decisóes e critérios; a segunda forma de poder -autônomo - consistia na capacidade de os trabalhadores colocarem em causa as próprias premissas da política e da gestão econômica. Essa forma de poder autônomo, por outro lado, constituía-se num "primeiro passo para a subordinação das exigências da produção às exigências humanas, tendo como última perspectiva a conquista do poder de autogestão" (Gorz, 1968, p. 15).

No contexto do final da década de 1990, a questão das reformas revolucionárias, ou não reformistas, emerge não mais tendo em vista o tema da autogestão da produção pelos operários, embora, para Gorz, ele ainda seja de teor anticapitalista. Agora, entre os temas que ilustram, em sua visão, as reformas não reformistas estão, por exemplo, a redução programada do tempo de trabalho, a alocação de uma renda de cidadania incondicional e o estímulo a atividades autônomas (artísticas, culturais, sociais, comunitárias), de alto valor social, mas sem valor de mercado (Silva, 2014, pp. 63-83). Ou seja, há um deslocamento não só na problemática ligada às reformas revolucionárias, mas também em suas formulaçôes teóricas e políticas, que de certa forma aproximam-no das discussões sobre justiça, presentes nos outros autores aqui discutidos. ${ }^{20} \mathrm{E}$ isso me leva a tratar algumas das formulaçóes de Axel Honneth, Nancy Fraser, Alain Caillé e Boaventura de Sousa Santos, conforme prometi no início deste texto, em termos do conceito de reformas revolucionárias mostrado acima - embora aqui eu faça isso apenas por meio de algumas indicações.

Um dos aspectos que mais me parece chamar a atenção na noção de reformas revolucionárias de Gorz é que ela consiste na tentativa de encontrar um elo, ou seja, uma maneira de vincular organicamente lutas sociais e as demandas imediatas a uma perspectiva de transformação social antissistêmica. Nesse sentido, entre os quatro autores discutidos ao longo deste texto, quem mais diretamente parece se aproximar da noção gorziana é Nancy Fraser, com seus remédios transformativos, seja na dimensão da redistribuição quando menciona explicitamente a renda básica incondicional, ${ }^{21}$ seja na do reconhecimento quando fala em desconstrução de identidades reificadas. Aliás, ao definir sua estratégia teórica e política de mudança social como via média, ela se refere explicitamente às reformas revolucionárias. No mais, sua ideia de paridade de participação, mutatis mutandis, também lembra a formulação de Gorz sobre poder autônomo.

Honneth, em seu debate com Fraser, também trata de transferência incondicional de renda, sobretudo vinculando-a à esfera dos direitos, a segunda de sua tipologia do reconhecimento. Mas é principalmente na própria gramática das lutas sociais, capturada pela noção de expectativas intuitivas de justiça, que me parece haver um possível elo com a ideia de reformas revolucionárias, principalmente por sua imanência intrínseca. Nesse caso, o que importa não é o conteúdo substantivo de determinada reivindicaçáo, mas a capacidade autônoma dos sujeitos envolvidos determinarem-na como pertinente ou não. E isso é levado a efeito tendo em vista um horizonte emancipatório. Mas o significado deste último não parece ser o mesmo para Gorz e para Honneth; isso é verdade, pelo menos no que se refere aos diagnósticos sobre o trabalho no capitalismo contemporâneo, já que enquanto Gorz (2004) fala em emancipação do trabalho e não pelo trabalho (assalariado), Honneth - que recentemente se declarou um hegeliano de esquerda (Honneth, 2015a) - continua apostando na ideia de emancipação na esfera do trabalho (Honneth, 2008; ver também Silva, 2010).

Em sua proposição de convivialismo, Alain Caillé também defende ideias como transferência incondicional de renda e faz uma crítica do utilitarismo que muito se aproxima da crítica de Gorz à expansão da forma mercadoria propiciada pela racionalidade econômica. Mas é na atenção que dá à questão ecológica e na radicalizaçáo da ideia de democracia como capacidade de "se opor sem se massacrar", de vivermos juntos sem mutuamente nos destruirmos, que reside uma chave interessante para se pensar uma estratégia de reformas que se aproxima daquela 
proposta por Gorz. Para ambos os autores, aliás, o nome de Ivan Illich ${ }^{22}$ é uma referência importante, seja na defesa do ambiente natural, seja na noção de convivialismo, como base de um socialismo democrático e ecologicamente sustentável.

É o projeto teórico de Boaventura de Sousa Santos, no entanto, que em seu desafio ao que chama pensamento abissal parece, pelo menos na terminologia, o mais radical, sem ao mesmo tempo deixar de procurar um caminho realista para levá-lo adiante. Ele também mantém a mesma disposição de procurar uma forma da democracia - de alta intensidade - que vá além da democracia representativa atualmente existente; nisso, aliás, ele se aproxima dos outros três. Mas ele ainda incorpora em seu projeto de uma sociologia das ausências e de uma sociologia das emergências a ideia de incluir novas experiências e saberes, em grande medida, deixados de lado pelo pensamento dominante (Santos, 2006; 2007). Aí também me parece haver algum parentesco com aquilo que Gorz denomina atividades autônomas, sem valor de mercado, mas com alto valor social e cultural, assim como na contraposição que o último faz entre saber e conhecimento. ${ }^{23}$

Creio que identificar os quatro autores como teóricos críticos, ainda que num sentido amplo, é possível porque, de certa forma, seus empreendimentos intelectuais seguem mais ou menos os passos que se costumam verificar nas teorias críticas: partem de diagnósticos de época, reconstruídos por meio de uma crítica imanente, que aponta para orientaçóes normativas. A despeito das diferenças entre os quatro, isso vale grosso modo para todos eles. Embora os diversos diagnósticos de época, por enfatizarem temas ou aspectos diferentes da realidade contemporânea, possam tornar uns mais radicais em suas críticas que outros, há alguns denominadores comuns que os aproximam, naquilo que venho sustentando desde o início deste texto, e que passam pela articulação das noções de justiça, democracia e socialismo, embora esses termos não signifiquem a mesma coisa para todos eles. Mas é dessa articulação entre justiça, democracia e socialismo que emergem as ideias de emancipação, presentes nos quatro, sempre com a noção de democracia aparecendo como chave principal, como se pode ver nas definiçóes de socialismo de cada um deles. Assim, o socialismo como liberdade social de Honneth (2014;
2015; 2015a), o socialismo feminista de Fraser (1989; 1997; 2003), o socialismo convivialista de Caillé (2011a) e o socialismo como democracia sem fim de Santos (2000) são todos intrinsecamente vinculados à ideia de democracia, ainda que o entendimento desta última difira de um autor a outro. É por meio da democracia, portanto, que se pode interferir nas diversas esferas ou dimensóes do todo social para pavimentar o caminho para uma sociedade melhor e mais justa. Isso, evidentemente, tem a ver com a noção de "via média" das reformas revolucionárias referidas no início deste artigo, sem esquecer que também faz lembrar, guardadas as diferenças, o socialismo democrático e ecológico defendido por André Gorz. Porém, quero deixar claro que, para mim, a pertinência da ideia de reformas revolucionárias remete basicamente à forma como ele concebe a dinâmica das mudanças sociais e não necessariamente seu conteúdo substantivo. ${ }^{24}$

Estou certo, por fim, de que essas quatro proposições teóricas, abrangentes e que se autodenominam críticas, embora também sejam elas próprias passíveis de crítica, têm algo a oferecer, a contribuir para a construção de alternativas que nos possibilitem almejar um mundo melhor. Suas análises podem nos ajudar a aprofundar a compreensão crítica dos diferentes âmbitos da realidade social; elas contribuem para que possamos abordar empaticamente os diversos movimentos sociais contemporâneos, sem perder o necessário distanciamento crítico e esclarecido que previne o teórico de se portar como mero porta-voz dos movimentos sociais. Enfim, embora cada uma das teorias se apresente como projeto relativamente autônomo em relação às outras, a despeito dos diálogos e debates já existentes entre alguns dos autores, creio que possam se enriquecer mutuamente e contribuir conjuntamente para uma sociologia crítica adequada às condições do mundo atual. Não foi outro, aliás, o meu intuito com estas reflexóes ainda preliminares e incompletas.

\section{Notas}

1 Ainda que a noção de sociologia crítica possa ser entendida num sentido bem mais amplo do que a empregada aqui (ver Ianni, 1996; Silva, 2012a), fiz minha escolha com base em critérios que creio ter dei- 
xado claros ao longo do texto; ainda assim, não fecho a possibilidade de incorporar em textos subsequentes outros autores ou autoras que não foram diretamente objeto do presente artigo, mas cujas contribuiçôes podem ser frutíferas para o projeto mais amplo que pretendo desenvolver; a propósito, um desses autores, mas nâo o único, que me vem à mente é Luc Boltanski, cujo trabalho será objeto de um próximo texto.

2 Cabe deixar claro, desde já, que o conceito de crítica no sentido aqui empregado reconhece a capacidade crítica dos atores e suas práticas, mas não abre mão do necessário distanciamento crítico da teoria; ou seja, não se limita a assumir, metodologicamente, a postura de participante, típica dos militantes de movimentos sociais. Na verdade, a relevância desse tema - conceito de crítica - merece por si só que se lhe dê um tratamento específico, que não cabe no âmbito deste artigo. Por ora, limito-me a remeter os leitores às seguintes referências: Benhabib (1986), Kauppinen (2002), Honneth (2009), Celikates (2012), Boltanski (2009; 2013).

3 Em relação ao Brasil, em especial ao grupo de teoria da Anpocs, ver Silva (2012, pp. 13-22); para o caso europeu, ver Genard (2015).

4 Ver nota 2.

5 A expressão "intersubjetividade forte" foi utilizada por Emil Sobottka durante o debate da versão preliminar deste texto, no Encontro da Anpocs, de 2014.

6 O fato de Nancy Fraser (2000) recorrer a Max Weber quando constrói seu conceito de reconhecimento como status não a torna estranha ao paradigma intersubjetivo, uma vez que sua noção de paridade de participação se mantém bem próxima e, a meu ver, também devedora do conceito habermasiano de democracia.

7 Para uma das primeiras críticas desse tipo, ver Alexander e Lara (1996); ver também Silva (2014, pp. 33-46).

8 As traduçôes das citaçóes em línguas estrangeiras são minhas.

9 Para uma sistematização das formulaçóes teóricas de Nancy Fraser, ver a interessante dissertação de Enrico B. P. Silva (2013).

10 Para uma boa introdução ao tema das epistemologias do Sul, ver Nunes (2010).

11 Para uma boa introduçấo ao tema da dádiva no debate contemporâneo, em especial ao grupo MAUSS, ver Martins (2008).

12 A propósito, o título do presente artigo inspira-se no mencionado texto de Fraser.

13 Sobre a distinção entre marxismo tradicional e marxismo náo tradicional, ver Postone (1993); para ele, marxismo tradicional é aquele que faz a crítica do capitalismo do ponto de vista do trabalho; já o marxismo não tradicional faz a crítica do trabalho no capitalismo.

14 Para o debate entre Fraser e Honneth, ver também Souza (2013).

15 Paul Ricoeur, assim como Caillé, também defende uma concepção de reconhecimento como gratidão, que se opóe à ideia de justiça como equivalência (Ricoeur, 2004).

16 Ao incluir a noção política de representação em seu modelo teórico, a teoria de justiça de Fraser passou de bidimensional (reconhecimento e redistribuição) para tridimensional (reconhecimento, redistribuição e representação).

17 Segundo Santos, "a Sociologia das Ausências é um procedimento transgressivo, uma sociologia insurgente para tentar mostrar que o que não existe é produzido ativamente como não existente, como uma alternativa não crível, como uma alternativa descartável, invisível à realidade hegemônica do mundo" (Santos, 2007, p. 28).

18 Ainda segundo Santos (2007), "A Sociologia das Emergências é a que nos permite abandonar essa ideia de um futuro sem limites e substituí-la pela de um futuro concreto" (Idem, p. 38); este último baseia-se nas possibilidades que existem no presente e que são sinais do futuro; mas essas possibilidades "são 'descredibilizadas' porque são embriôes, porque são coisas não muito visíveis na forma de sinais, pistas, possibilidades" (Idem, p. 37).

19 Vale lembrar que o termo "reforma", conforme aparece nesses debates, nada tem a ver com o sentido que aparece no noticiário da imprensa e nas políticas neoliberais contemporâneas, em que "reforma" significa supressão de direitos sociais e a mercantilização daquilo que antes constituía a base do Estado de bem-estar social: educação, saúde etc.; ou seja, esta última deveria na verdade ser chamada de contrarreforma, já que consiste num desmonte do sistema de bem-estar com a supressão de direitos duramente conquistados e a privatização dos serviços.

20 Para uma visão mais abrangente da obra de Gorz, ver Silva (2011).

21 Para a relação entre renda básica e socialismo, ver também Wright (2006).

22 Ver em especial o texto "La convivencialidad" (Illich, 2006, pp. 369-530).

23 Vale atentar para a distinção que Gorz faz entre saber e conhecimento; para ele, enquanto o segundo pode ser 
codificado e transformado em mercadoria pelo capital, o primeiro, intrinsecamente ligado a quem o coloca em prática, não se prestaria a ser apropriado pelo capital e transformado em mercadoria (Gorz, 2005).

24 Com isso também deixo claro que não pretendo forçar a aproximação das análises desses quatro autores com as formulaçóes de Gorz, cujo anticapitalismo é bem mais explícito (Gorz, 2010) que o da maioria deles.

\section{BIBLIOGRAFIA}

ALEXANDER, JEFFREY \& LARA, Mara P. (1996), "Honneth's New Critical Theory of Recognition", New Left Review, 220: 126-136. BENHABIB, Seyla. (1986), Critique, Norm, and Utopia. Nova York, Columbia University Press. (2009), De la critique: précis de la sociologie de l'émancipation. Paris, Gallimard.

(2013), "Sociologie et critique sociale: de la sociologie critique à la sociologie de la critique et retour". Palestra proferida no IFCH-Unicamp em 21/8/3013.

CAILLE, Alain. (1986), Splendeurs et misères des sciences sociales, Genève, Librairie Droz.

. (1989), Critique de la raison utilitaire. Paris, La Découverte.

. (1993), La démission des clercs: la crise des sciences sociales et l'oubli du politique. Paris, La Découverte.

. (1994), "Présentation", Revue du Mauss, 23: 3-28.

(2000), Anthropologie du Don. Paris, Desc-

lée de Brouwer.

. (2006), "O Dom entre interesse e desinteressamento", in Paulo Henrique Martins e Roberta Bivar C. Campos (orgs.), Polifonia do Don, Recife, Editora UFPE, pp. 25-66.

(org.). (2007), La quête de reconnaissance.

Paris, La Découverte.

. (2008), "Reconhecimento e Sociologia". Revista Brasileira de Ciências Sociais, 23 (66): 151-163.

. (2009), Théorie anti-utilitariste de l'action.

Paris, La Découverte.

. (2011), Pour un manifeste du convivialisme. Paris, Le Bord de l'Eau. (2011a), "Du convivialisme vu comme um socialisme radicalisé e universalisé (et reciprocament)", in Alain Caillé et al., Da la convivialité, Paris, La Découverte, pp. 73-98.

(2014), Anti-utilitarisme et paradigme du don. Pour quoi? Lormont, Le Bord de l'Eau.

CAILLÉ, Alain et al. (2013), Manifesto convivialista. São Paulo, Annablume.

CELIKATES, Robin. (2012), "O não reconhecimento sistemático e a prática da crítica: Boudieu, Boltanski e o papel da Teoria Crítica”. Novos Estudos, 93: 29-42.

ENGELS, Friedrich. (1975), "Do socialismo utópico ao socialismo científico", in Karl Marx e Friedrich Engels, Textos, vol. 1, São Paulo, Edições Sociais, pp. 5-60.

FRASER, Nancy. (1980), Adjudicating between competing social descriptions: the critical, empirical and narrative dimensions (with an application to Marxism). PhD dissertation. Nova York, City University of New York.

(1989), Unruly practices. Mineapolis, Minnesota University Press.

. (1997), Justice interruptus. Nova York/Londres, Routledge. . (2000), "Rethinking recognition". New Left Review, 3: 120.

. (2001), "Da redistribuição ao reconhecimento? Dilemas da justiça na era pós-socialista", in Jessé Souza (org.), Democracia hoje, Brasília, Editora da UnB, pp. 245-282.

(2003a), "Social justice in the age of identity politics: reditribution, recognition, and participation", in Nancy Fraser e Axel Honneth, Redistribution or recognition, Londres, Verso, p. 7-109. . (2009a), Scales of justice. Nova York, Columbia University Press.

(2009b), "Feminism, Capitalism and the Cunning of History". New Left Review, 56: 97117.

. (2011), "Mercantilização, proteção social e emancipaçáo: as ambivalências do feminismo na crise do capitalismo". Revista Direito GV São Paulo, 7 (2): 617-634.

. (2013), "A triple movement? Parsing the politics of crisis after Polanyi", New Left Review, 81:119-132. 
FRASER, Nancy \& HONNETH, Axel. (2003), Redistribution or recognition. Londres, Verso.

FRÈRE, Bruno. (2015), "La relance de la critique", in ___ (ed.), Le tournant de la théorie critique, Paris, Desclée de Brouwer, pp. 7-34.

GENARD, Jean-Louis. (2015), "Sociologie critique, sociologie morale”, in Bruno Frère (ed.), Le tournant de la théorie critique, Paris, Desclée de Brouwer, pp. 37-65.

GORZ, André. (1968), Estratégia operária e neocapitalismo. Rio de Janeiro, Zahar Editores. . (2004), Misérias do presente, riqueza do futuro. São Paulo, Annablume.

(2005), O imaterial: conhecimento, valor e capital. São Paulo, Annablume.

(2010), Ecológica. São Paulo, Annablume.

HABERMAS, Jürgen. (1987), The philosophical discourse of modernity. Cambridge (MA), MIT Press.

(2012), Teoria do agir comunicativo. São Paulo, Martins Fontes, 2 vols.

HEGEL, Georg W. F. (1967), Philosophy of right. Londres, Oxford University Press.

HONNETH, Axel. (1991), The critique of power: reflective stages in a critical social theory. Cambridge (MA), MIT Press.

. (1994), "The social dynamics of disrespect: on the location of critical theory today". Constellations, 1 (2): 255-269.

(1995), The fragmented world of the social. Albany, NY, Suny University Press.

. (2001a), "Recognition or redistribution? Changing perspectives on the moral order of society". Theory, Culture \& Society, 13 (2-3): 43-55.

. (2001b), "Democracia como cooperação reflexiva: John Dewey e a teoria democrática hoje", in Jessé Souza (org.), Democracia hoje, Brasília, Editora da UnB, pp. 63-91.

(2001c), "Invisibility: on the epistemology of 'recognition'", Proceedings of the Aristotelian Society, suppl. 75: 111-126.

(2003a), Luta por reconhecimento. São Paulo, Editora 34.

. (2003b), "Redistribution as recognition: a response to Nancy Fraser", in Nancy Fraser e Axel Honneth, Redistribution or recognition, Londres, Verso, pp. 110-197.
. (2004), "Recognition and justice: outline of a plural theory of Justice". Acta Sociologica, 47 (4): 351-364.

. (2007), Sofrimento de indeterminação. São Paulo, Singular.

. (2008), "Trabalho e reconhecimento: tentativa de uma redefinição", Civitas, 8 (1): 4667.

(2009), "Reconstructive social criticism with a genealogical proviso: on the idea of 'critique' in the Frankfurt School", in __, Pathologies of reason, Nova York, Columbia University Press, pp. 43-53.

. (2012) The I in we: studies in the theory of recognition. Cambridge, Polity Press.

. (2014), Freedom's right: the social foundations of democratic life. Nova York, Columbia University Press.

. (2015), Die Idee des Sozialismus: Versuch einer Aktualisierung. Berlim, Suhrkamp.

. (2015a), "Rejoiner". Critical Horizons, 16 (2): 204-226.

HORKHEIMER, Max. (1983), "Teoria tradicional e teoria crítica”, in Benjamin, Habermas, Horkheimer, Adorno: textos escolhidos. São Paulo, Abril Cultural, pp. 117-154.

IANNI, Octávio. (1996), "A sociologia de Florestan Fernandes". Estudos Avançados, 10 (26).

ILLICH, Ivan. (2006), Obras reunidas I. Cidade do México, Fondo de Cultura Económica.

KAUPPINEN, Antti. (2002), "Reason, recognition, and internal critique". Inquiry, 45: 479-498.

MARTINS, Paulo Henrique. (2008), "De Lévi-Strauss a MAUSS - Movimento Antiutilitarista nas Ciências Sociais: Itinerários do dom". Revista Brasileira de Ciências Sociais, 23 (66): 105-130.

MAUSS, Marcel. (2003), Sociologia e antropologia. São Paulo, Cosac Naify.

MILLER, David. (1976), Social justice. Oxford, Clarendon Press.

. (1999), Principles of social justice, Cambridge, MA, Harvard University Press.

NUNES, João Arriscado. (2010), "O resgate da epistemologia”, in Boaventura de Sousa Santos e Maria Paula Meneses (orgs.), Epistemologias do Sul, São Paulo, Cortez, pp. 261-290. 
POSTONE, Moishe. (1993), Time, labor, and social domination: a reinterpretation of Marx's critical theory. Nova York, Cambridge University Press.

RICOEUR, Paul. (2004), Parcours de la reconnnaissance. Paris, Stock.

SANTOS, Boaventura de Sousa. (1999), "Por que é tão difícil construir uma teoria crítica?”. Revista Crítica de Ciências Sociais, 54: 197-215.

. (2001), "Nuestra America: reinventing a subaltern paradigm of recognition and redistribution". Theory, Culture \& Society, 13 (2-3): 185-217.

(org.). (2003), Reconhecer para libertar. Rio de Janeiro, Civilização Brasileira.

. (2006), A gramática do tempo. Sáo Paulo, Cortez.

(2007), Renovar a teoria crítica e reinventar a emancipação social. São Paulo, Boitempo.

. (2010), "Para além do pensamento abissal: das linhas globais a uma ecologia de saberes", in Boaventura de Sousa Santos e Maria Paula Meneses (orgs.), Epistemologias do Sul, São Paulo, Cortez, pp. 31-83.

. (2010a), "Um Ocidente não ocidental? A filosofia à venda, a douta ignorância e a aposta de Pascal", in Boaventura de Sousa Santos e Maria Paula Meneses (orgs.), Epistemologias do Sul, São Paulo, Cortez, pp. 519-562.

. (2011), "Hacia una política emancipadora de las ciencias sociales en América Latina (entrevista com Álvaro Márquez-Fernandez)". Utopia y Praxis Latinoamericana, 16 (54): 139-143.

SILVA, Enrico P. B. da. (2013), A teoria social crítica de Nancy Fraser: necessidade, feminismo e justiça, Dissertação de mestrado. Campinas, IFCH-Unicamp.

SILVA, Josué Pereira da. (2008), Trabalho, cidadania e reconhecimento. São Paulo, Annablume.

. (2010), "Sobre a relação entre trabalho e reconhecimento na teoria de Axel Honneth: uma nota crítica". Trabalho apresentado no $34^{\circ}$ Encontro Anual da Anpocs. Caxambu, MG, 25-29 out. . (2011), André Gorz: trabalho e política. São Paulo, Annablume.
(2012), "Teoria Social no Brasil: balanço preliminar de uma experiência recente", in Josué Pereira da Silva (org.), Sociologia crítica no Brasil, São Paulo, Annablume, pp. 13-22.

(org.). (2012A), Sociologia crítica no Brasil. São Paulo, Annablume.

. (2014), Por que renda básica? São Paulo, Annablume.

SOUZA, Luiz Gustavo C. (2013), Reconhecimento, redistribuição e as limitaçôes da teoria crítica contemporânea. Tese de doutorado. Campinas, IFCH-Unicamp.

WRIGHT, Eric Olin. (2006), "Basic income as a Socialist project”. Basic Income Studies, 1 (1). 


\section{O QUE É CRÍTICO NA SOCIOLOGIA CRÍTICA?}

\author{
Josué Pereira da Silva
}

Palavras-chave: Reformas revolucionárias; Axel Honneth; Nancy Fraser; Alain Caillé; Boaventura de Sousa Santos.

$\mathrm{O}$ artigo visa a discutir as possibilidades de uma sociologia crítica capaz de lidar com as demandas do presente. Com base no conceito norteador de reformas revolucionárias de André Gorz, analiso algumas proposiçóes social-teóricas. Minhas referências são as teorias de Axel Honneth, Nancy Fraser, Alain Caillé e Boaventura de Sousa Santos. Empreendo minha análise com base em três ideias que permitem vislumbrar nessas teorias um núcleo comum: a busca de uma abordagem intersubjetivista; a ênfase normativa na necessidade de buscarmos caminhos que nos permitam viver juntos, sem ignorar nossas diferenças; e a busca política de um caminho que nos guie na busca de mudanças sociais que evitem extremismos de direita e de esquerda. Isso possibilitou delinear os traços principais de uma sociologia crítica adequada aos desafios do presente e realçar as contribuiçóes desses teóricos à sociologia crítica.

\section{WHAT IS CRITICAL ABOUT CRITICAL SOCIOLOGY?}

Josué Pereira da Silva

Keywords: Revolutionary reforms; Axel Honneth; Nancy Fraser; Alain Caillé; Boaventura de Sousa Santos.

This article aims to discuss the possibilities of a critical sociology capable of dealing with the challenges of our time. Based on André Gorz's concept of revolutionary reforms, I analyze some social-theoretical models. As references for this work, I rely on the theories of Axel Honneth, Nancy Fraser, Alain Caillé, and Boaventura de Sousa Santos. The analysis is developed on the basis of three ideas which permit us to find in these theories a unifying denominator: the search for an inter-subjective approach; a normative emphasis guided by the need to find ways of living together, despite our differences; and a political search for non-extremist forms of social changes, which can be defined as 'via media'. These ideas may allow us to delineate the main characteristics of a critical sociology adequate to the challenges of our time as well as to highlight the contributions these theorists give to critical sociology.

\section{QU'EST-CE QUI EST CRITIQUE DANS LA SOCIOLOGIE CRITIQUE?}

Josué Pereira da Silva

Mots-clés: Réformes révolutionaires; Axel Honneth; Nancy Fraser; Alain Caillé; Boaventura de Sousa Santos.

Cet article propose une discussion sur les possibilités d'une sociologie critique capable d'aborder les problèmes de la société actuelle. Guidé par le concept de réformes révolutionaires d'André Gorz, nous analysons quelques modèles sociaux-théoriques. Nos références sont les theories d'Axel Honneth, de Nancy Fraser, d'Alain Caillé et de Boaventura de Sousa Santos. Nous entreprenons cette analyse ayant pour base trois idées qui permettent d'entrevoir un noyau commun à ces théories: la cherche d'un abordage intersubjectiviste; l'importance normative dans le besoin de trouver des voies qui nous permettent de vivre ensemble, sans ignorer nos différences et qui, politiquement, nous guident dans la recherche de changements sociaux qui évitent les extremismes de la droite et de la gauche. Cela nous a permis de tracer les principaux aspects d'une sociologie critique capable de faire face aux défis du présent et de mettre en avant les contributions de ces théoriciens de la sociologie critique. 